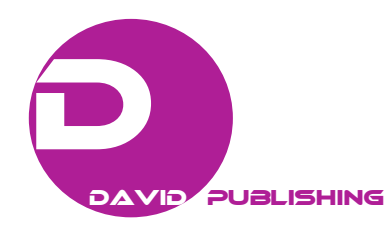

\title{
BIM Software Plug-ins: An Alternative to Optimize Design Processes from the Perspective of Performance and Sustainability
}

\author{
Juliano Lima da Silva ${ }^{1}$, Andréa Quadrado Mussi ${ }^{1}$, Lauro André Ribeiro ${ }^{1,2}$ and Thaísa Leal da Silva ${ }^{3}$ \\ 1. Postgraduate Program in Architecture and Urbanism (PPGARQ) of the Polytechnic School at Faculdade Meridional (IMED), \\ Passo Fundo/RS. CEP: 99070-220, Brazil; \\ 2. INESC Coimbra, Coimbra CEP 3030-030, Portugal; \\ 3. School of Computer Science of the Polytechnic School at Faculdade Meridional (IMED), Passo Fundo/RS. CEP: 99070-220, \\ Brazil
}

\begin{abstract}
With the increased use of technology in design processes, BIM (building information modeling) tools user's community has started to develop solutions through external applications such as plug-ins to automate specific and repetitive tasks, amplify interoperability and add functionality versatility to BIM platforms. This paper seeks to evaluate Autodesk Revit platform plug-ins' state of the art, by means of a quantitative study of current repositories and the proposition of a categorization system of the purposes to which plug-ins are developed. Then a comparison between use and necessity of Brazil's AEC (architecture, engineering and construction) industry was done through a questionnaire with experienced professionals of the area. An analysis was carried out based on the professional's difficulties in meeting the requirements of Brazilian Performance Standard and compliance with Environmental Certification provisions, underpinning the possibility of using plug-ins to optimize the design processes under the perspective of performance and sustainability.
\end{abstract}

Key words: Building information modeling, plug-ins, performance standard, environmental certifications.

\section{Introduction}

BIM (building information modeling) has become one alternative for productivity development in the AEC (architecture, engineering and construction) sector, and professionals can count on the consistency and timing of a tridimensional information model endowed with relevant, intelligent and interconnected data, to improve design, detailing and management of complex projects [1].

The adoption of BIM technology in its different stages can modify project culture already established in offices and construction companies as it inserts concepts of cooperation and integration in technology, policy and process interfaces [2], instead of designing

Corresponding author: Juliano Lima da Silva, civil engineer; research fields: BIM, design processes and building performance. E-mail: juliano_lima_silva@hotmail.com. in a sequential, fragmented, documentation-centric way, professionals can contribute collaboratively through a federated model, complemented by architecture, structural and MEP (mechanical, electrical and plumbing) systems disciplines, an information-centric model that allows designers of each instance to contribute in project decision making, aware of the particularities of others involved. Such changes may require the assistance of BIM coordinators, professionals specialized in modeling compatibility and coordination, who carry out the technology implantation in the processes [3].

In Brazil, the performance standard, NBR 15.575-Residential Buildings-Performance [4], recently transformed the AEC industry, requiring suppliers and designers to adapt to new production processes. Architects and engineers revamp their 
design processes to match specifications related to construction systems' comfort, safety and durability; such control requirements demand detailed building information and improvements in decision-making.

From another perspective, the growing interest in sustainable design, given by environmental certifications such as LEED (leadership in energy and environmental design) and BREEAM (building research establishment environmental assessment method), has become a way of guiding planning processes and technological decision making, altering design processes while taking into account environmental impacts and influences of the constructive system choices along the building life cycle [5].

One aspect of BIM technology is the use of applications external to the main platforms, tools known as plug-ins, which use the programming already established by the BIM software to manipulate different features of the design environment, possessing defined purposes, focused on adding versatility to existing functionalities. BIM professionals can use the plug-ins to achieve particular goals of design processes, as well as to increase their productivity, letting the applications execute repetitive tasks, perform calculations or run commands in sequence through programming routines, among other uses.

The process of developing plug-ins is currently given by the community of BIM technology users, who look for specific solutions for a variety of project situations. One of the prominent communities is Autodesk App Store, composed of members who use the authoring tool Autodesk Revit, which through its Application Programming Interface (API) allows them to interact with the tool's functionalities, enabling the production of content for the repository [6].

There is a knowledge gap in solution optimization and academic research about external applications such as BIM software plug-ins, the importance of this paper lies in the diagnosis of use of these tools by Brazil's AEC industry professionals, seeking through a survey directed to BIM technology users, to elucidate how plug-ins are implemented in their design processes, as well as if the tools meet expectations of use and what are the possible interactions with NBR 15.575 and environmental certifications.

\section{Theoretical Reference}

The potential of tailoring an existing software to specific project needs lies in the increased range of possibilities and to overcome platform limits, even though customizing a software to specific user needs is a new practice in architecture, it has already been widely implemented in mechanical engineering and design [7].

In Brazil, recent research has been done integrating BIM and energy efficiency, by highlighting the possibilities of use of computational tools directed to a variety of performance aspects assessment, with the objective of early design process improvements [8]. Among the added possibilities of using external tools to complement design processes, also stands out the project integration and information sharing provided by plug-ins along BIM platforms, which subsidizes project management by facilitating BIM model interaction, providing support to existing management features and encouraging holistic project development [9].

Plug-ins can also be used to facilitate cost, scheduling and sustainability analysis for construction projects, while these tasks are usually complicated by the several constructive system alternatives, along with the ever-changeable design processes and decision making, an external tool can, for example, help to increase synchronization and automate processes by interrelating the model's existing information with another external software or servers that contain data relevant to the task at hand, allowing for agile decision making and a larger pool of solution possibilities [10].

Even though the importance of sustainable design has been growing in the construction industry, energy and performance analysis still do not have the required 
integration to BIM design processes, with these steps usually being fulfilled only after the architectural design is completed [11]. In such environment, plug-ins can increase the viability of assessing different technological solutions at the project's initial stages, allowing designers to focus on achieving less negative impacts on building life cycle and energy efficient design [5].

Through plug-ins created in the Revit API (application programming interface), framework to assess requirements for environmental certifications such as LEED can be integrated into design processes [12], allowing designers to insert contextual information on the building model in order to achieve certain certification credits, moreover, the document submission can be managed according to the designer's goals. Focusing on specific fields of certification such as for rainwater management [13], operational energy use, carbon emissions [14] and sustainable materials [15] are also practices of plug-in implementation, which allow for more strategic design choices in certification processes.

\section{Methodological Procedures}

The methodology of this paper starts with a two-part study: first, a quantitative search of existing plug-in repositories for the authoring tool Autodesk Revit is done, so they can be separated in categories and the state of the art of these applications can be shown. Then, by means of an interview with AEC professionals, a qualitative questionnaire is carried out, allowing discussion about the challenges and paths to be taken in the field of technological innovation related to external applications in BIM software.

The choice for Autodesk Revit authoring tool for plug-in searching comes from two reasons: firstly, because of its API, functionalities and possibilities, a tool that allows users to modify and customize internal interactions of Revit platform through routines, enabling design of a diversity of utilities that are manifested as plug-ins. Secondly, the presence of an established community, Autodesk App Store members that develop, upload, rate and discuss produced content.

\subsection{Plug-In Repositories Assessment}

The Revit plug-in's state of the art searching is done through exploratory analysis of existing repositories, taking Autodesk App Store as the main content source, which, as of the date of this study, possesses 583 Revit plug-ins available for purchase or download, divided in 15 default categories. The search is then complemented by secondary repositories, which are characterized in this paper as websites that contain at least 3 Revit plug-ins available for purchase or download.

However, albeit a solid starting point for beginners, the categories proposed by Autodesk App Store have very varied concepts, which may have different interpretations from the peer who submits the plug-in, who may also select multiple categories and consequently have irregular concepts about the plug-in categorization. This process is further complicated by the fact that the filtering system does not intersect multiple categories, which means that selecting multiple filters will show repositories in an additive way, not subtracting information between them and making the definition of plug-in usage more difficult.

A new categorization is proposed, in a way so that the quantitative plug-in amount searched in the repositories can be grouped in classifications defined by keyword-based criteria. The initial category definition is done through comparative analysis of the text present in several plug-ins, words that are repeated more in certain plug-ins, inserted in related and compatible contexts with each other, form a new category. The proposed categories are:

- Structural: tools related to structural design, calculation, dimensioning, detailing and analysis, presenting materials like concrete, steel and timber in situations where they act as structural elements: beams, columns, slabs, roofs, bracing, trusses, foundation, among others; 
- MEP—-mechanical, electrical and plumbing: tools associated with complementary building projects such as mechanical, electrical and hydraulic installations and facilities, or to serve as subsidy for flow, pressure, circuits or ventilation system calculations;

- Performance: tools focused on performance, building life cycle assessment, energetic efficiency, thermal, acoustic and light comfort, water consumption, sustainable materials and emission control, plug-ins related to building environmental sustainability;

- Productivity: tools connected to schedules and workflows, used to generate reports, quantity take-off and help in performing repetitive tasks in design processes, used to streamline designers' activities or to automate actions;

- Conversion: tools with the sole purpose of converting files, being able to import and export a variety of formats with the objective of enabling interoperability between software or the generation of documentation;

- Component: tools related to parametric design of walls, windows, doors and other family components, as well as product detailing and graphic representation improvement, annotation tools and rendering related applications.

Then, each of the main and secondary repositories' plug-ins is filtered by a tool denominated plug-in detection device: the text in the name, presentation, features and characteristics of the plug-in are analyzed, the keywords are counted and the category which possesses the higher number of compatible keywords (Fig. 1) classifies the plug-in in it, in the case of a draw or if the plug-in detection device does not elucidate a category sufficiently, a re-reading of the text of the plug-in description is made and the category context that most closely resembles the proposed features qualifies the plug-in.

\subsection{Professional Plug-in Use Diagnosis}

The second part of the study consists of a qualitative questionnaire composed of five sections, created from
Table 1 Proposed categories' keywords

Structural: structure, steel, bridge, frame, beam, column, concrete, wood, reinforce, brace, timber, slab, truss, analysis, robot.

MEP: duct, MEP, pipe, pip, circuit, pressure, water, flow, fixture, cable, ceiling, ventilation, conduit, electric, hanger. Performance: environment, performance, impact, cycle, assess, energy, heat, efficiency, thermal, consumption, daylight, eco, rain, certification, illumination.

Productivity: table, sheet, schedule, quantification, takeoff, take-off, automatic, quick, annotation, filter, workflow, estimation, productivity, purge, provide.

Conversion: ifc, convert, export, dwg, link to, import, share, extract, enhance, external, document, dxf, server, excel.

Component: wall, window, parameter, dimension, room, family, product, detail, curtain, component, factory, seek, families, section, render.

Google Forms, with the objective of diagnosing the design practices of AEC professionals in the field of BIM tool usage, seeking understanding on how plug-ins are implemented in design processes, which are the most used types of applications and if they are effective in achieving their purposes.

The questionnaire is composed of three types of responses: characterization responses, free narrative responses and Likert scale responses. Characterization responses are presented solely for displaying the professional profile and activities of the respondents, with questions of single or multiple alternative selection. Likert scale responses are gathered in questions where the respondents must express their opinion about statements with five possible positions (1 for totally disagree, 5 for totally agree).

In free narrative responses, professionals answer questions by text boxes in the questionnaire. The most notorious answers are selected, while similar answers are concatenated. This is made to further highlight characterization and generate discussions based on the professionals' perceptions about design processes.

Following professional's characterization, an analysis of possible plug-ins related to NBR 15.575 aspects and environmental certifications is made, through two specific sections to diagnose possibilities of integration between BIM and the Brazilian standard and the certifications' requirements, respectively.

The questionnaire is sent by email to several 
recipients in an exploratory manner, with selection criteria defined as: AEC professionals in Brazil, who work in offices, institutions or construction companies, and utilize BIM technology in their design processes and have knowledge of external platform tools, performance standard and environmental certification processes.

\subsection{Questionnaire Structure}

Firstly, a declaration of consent is presented highlighting the questionnaire's academic purpose, then in Section 2, data on respondent general information is collected for sample characterization: number of project team members, educational background, professional position, project experience time, BIM technology experience time and project types that develop.

Respondents design process is then characterized, with questions related to BIM platforms they utilize, common uses of platforms in work routines, communication between designers and questions about information model sharing processes.

Plug-in and extension concepts are then presented in the questionnaire through Section 3, where respondents answer questions about productivity, utility and usage of programming in design processes, if and which plug-ins are used, as well as if they have developed plug-ins. Lastly, respondents may demonstrate their need for solutions in a specific area, by suggesting and describing a plug-in they would like to be developed.

In Section 4, questions about integration between BIM and NBR 15.575 are made by a Likert scale, respondents may demonstrate partiality as to the feasibility of current BIM technology to be able to assist design process under different perspectives, divided into areas of concentration based on NBR 15.575 aspects.

Moreover, the respondents are asked about the possibility of plug-in usage focused on project practice that incorporates the requirements of the performance standard of housing development, then by free narrative response, they can explicit the main difficulties in implementing such requirements in design process.

In Section 5, the respondents answer if they have ever been involved in environmental certification processes such as: LEED, BREEAM, Aqua, Selo Azul or ISO 14001, Likert scale questions about BIM integration with common requirements among the different green seals are presented and again, the respondents may demonstrate partiality as to BIM usage in sustainable building projects and the possibility of use of plug-ins developed for this purpose, as well as a narrative response to highlight the major obstacles in certification processes.

\subsection{Comparative Studies}

Through presentation of Revit plug-ins' state of the art and diagnosis of plug-in used by professionals, it is possible to compare the availability of plug-in categories in repositories with the plug-ins used and suggested by the professionals. This is done by intersection between questionnaire informed data and the proposed plug-in categorization.

The questionnaire is then used to validate the categories proposed in the state of the art, as well as to add plug-ins that were undiscovered or that were not covered in the methodological procedures to the state of the art of the database, therefore, serving as means of feedback.

The narrative responses, where the respondents explicit the plug-ins they utilize and suggest, are interpreted and then used for comparison with the state of the art presented, to assess if what is produced in the repositories reflects the use and needs of the questioned professionals.

Discussion about performance category can be made by questions related to Brazilian Performance Standard and environmental certifications, enabling analysis and perception of possibility, relevancy and utility of plug-ins of this category in the current scenario. 


\section{Results and Discussion}

\subsection{State of the Art of the Revit Plug-ins}

Quantitative result on repository research enables identification of which plug-ins are the most commonly produced by the community, as well as what paths this segment of BIM technology development is heading.

By exploratory analysis of current repositories, it was possible to collect 583 Autodesk Revit plug-ins from Autodesk App Store and 214 plug-ins from secondary repositories, for a total of 797 applications found (Table 2), within which 16 were added from professionals' survey suggestion, a stage of this study that will be detailed later.

All plug-ins passed through the plug-in detection device, a tool conceived in Microsoft Excel to perform keyword occurrence analysis in the plug-ins' description texts, in order to determinate its dominant category in a graphical manner, as exemplified in Fig. 1.

Then, by exhaustive analysis of repository content and separation of plug-ins in their matching dominant categories, the state of the art of plug-ins developed for Revit as of the date of this study can be explicited, as shown in Fig. 2.

Analyzing the results, it becomes possible to verify a considerable quantity of external applications being developed with various file conversion purposes, as well as tools with the objective of manipulating and detailing components, however, the most prominent category is productivity, which represents that $36.17 \%$ of the plug-ins analyzed are developed to automate repetitive tasks, manipulate schedules and workflows, among other uses related to this category.

Although performance category description encompasses a considerable number of contexts and concepts, covering areas such as comfort, sustainability, performance and life cycle analysis plug-ins, only a total of 27 plug-ins $(3.38 \%$ of the state of the art) related to these purposes were found. Seeking to understand the reason of this event, this fact was taken

Table 2 Plug-in repositories.

\begin{tabular}{ll}
\hline Plug-in repositories & Number \\
\hline Autodesk App Store [16] & 583 \\
Tools4revit [17] & 23 \\
AGACAD [18] & 33 \\
AEC-APPS [19] & 54 \\
CASE Apps [20] & 44 \\
Kiwicodes [21] & 12 \\
BIM Interop. Tools [22] & 4 \\
RevitWorks [23] & 5 \\
David Pinto [24] & 3 \\
CGS Plus [25] & 9 \\
IdeateSoftware [26] & 4 \\
RTVTOOLS [27] & 7 \\
Survey Suggested & 16 \\
\hline TOTAL & 797 \\
\hline
\end{tabular}

STRUCTURAL

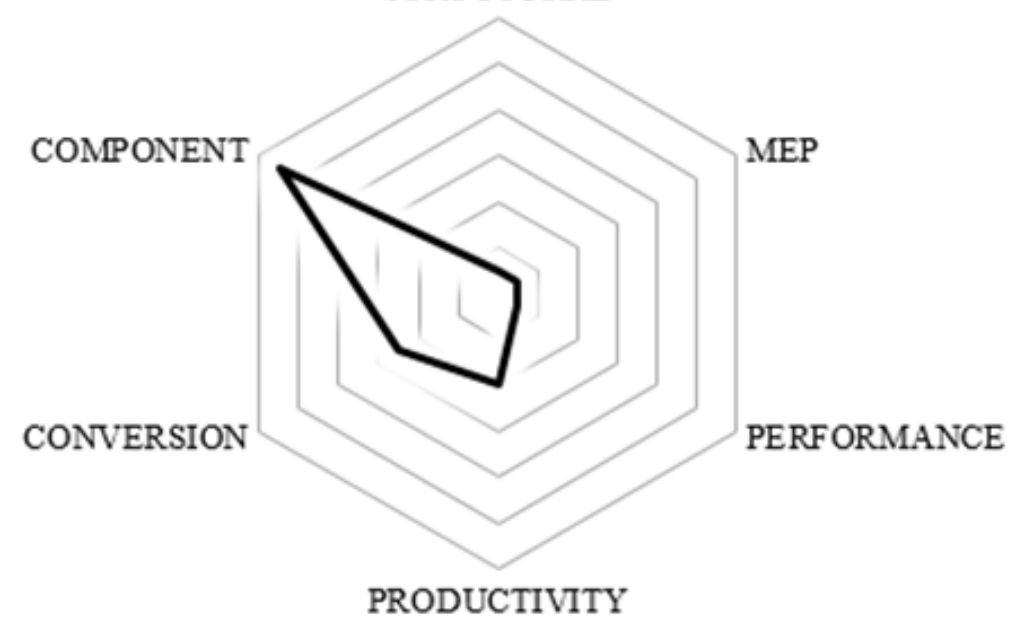

Fig. 1 Plug-in detection device classifies a plug-in as component-based. 


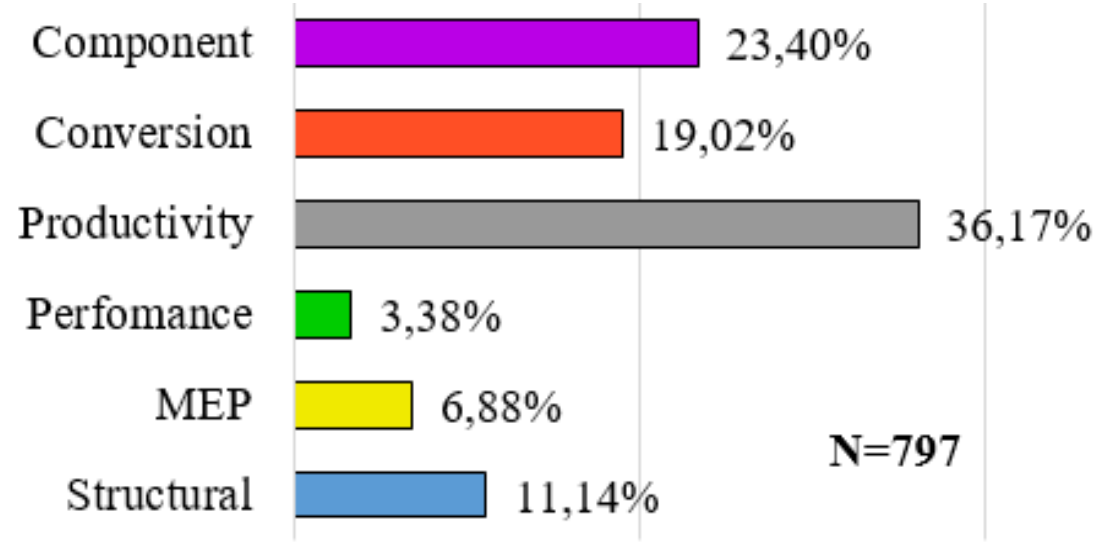
$0,00 \%$
$20,00 \%$
$40,00 \%$

Fig. 2 The state of the art of the Revit plug-ins.

as a subsidy to support part of the questionnaire directed to BIM technology professionals, which will be discussed next.

\subsection{Surveyed Professionals Characterization}

The questionnaire was sent by e-mail to the recipients following methodology criteria and as a result, covered 29 professionals. According to characterization steps, the questionnaire is composed with professionals graduated in schools of architecture (62.07\%), civil engineering (34.48\%) and business (3.45\%), moreover, some respondents stated they also graduated in areas such as electrical engineering, design and building technician course. The respondents work in offices, institutions or companies in Brazil, located predominantly in the states of Rio Grande do Sul (10 respondents) and São Paulo (8 respondents), other locations are Rio de Janeiro, Paraná, Paraíba, Mato Grosso (2 respondents each), Goiás, Distrito Federal and Bahia (1 respondent each).

As for the number of members in the full team, results concentrate in teams of up to 4 people (44.4\%) and teams of 11 to 20 people (25.9\%), as for the number of members in the project team, many professionals declared to work as autonomous (30.8\%) or in teams of 11 to 20 project members (19.2\%).

When questioned about their professional positions or activities they perform in design processes (being able to select more than one alternative), the predominant category is that of BIM coordinator (62.07\% of respondents), as shown in Fig. 3, in the field "other" (20.69\% of respondents), some professionals filled a text box with activities related to education such as: instructor, researcher and professor.

The working time with projects was declared to be 6 to 10 years in $27.6 \%$ of responses, and more than 10 years in $48.3 \%$, demonstrating that the profile of the respondents is that of professionals potentially experienced in project practice. Working time with projects specifically using BIM technology was declared as less than 2 years in $10.3 \%$ of responses, 2 to 4 years in 31\%, 4 to 6 years in $17.2 \%, 6$ to 10 years in $13.8 \%$ and more than 10 years in $27.6 \%$ of responses, which allows to observe a variability in the adoption of BIM technology throughout the years by different companies in various locations in Brazil.

Professionals declared to develop project related activities in diverse disciplines and purposes: architecture (77.8\%), planning/execution (51.9\%), hydraulic (44.4\%), structural (40.7\%), electrical (40.7\%) and interiors (37\%), on various project typologies, with the most common to the respondents being buildings related to: commercial/services (82.8\%), multi-family residences (72.4\%) and single family residences (62.1\%). 


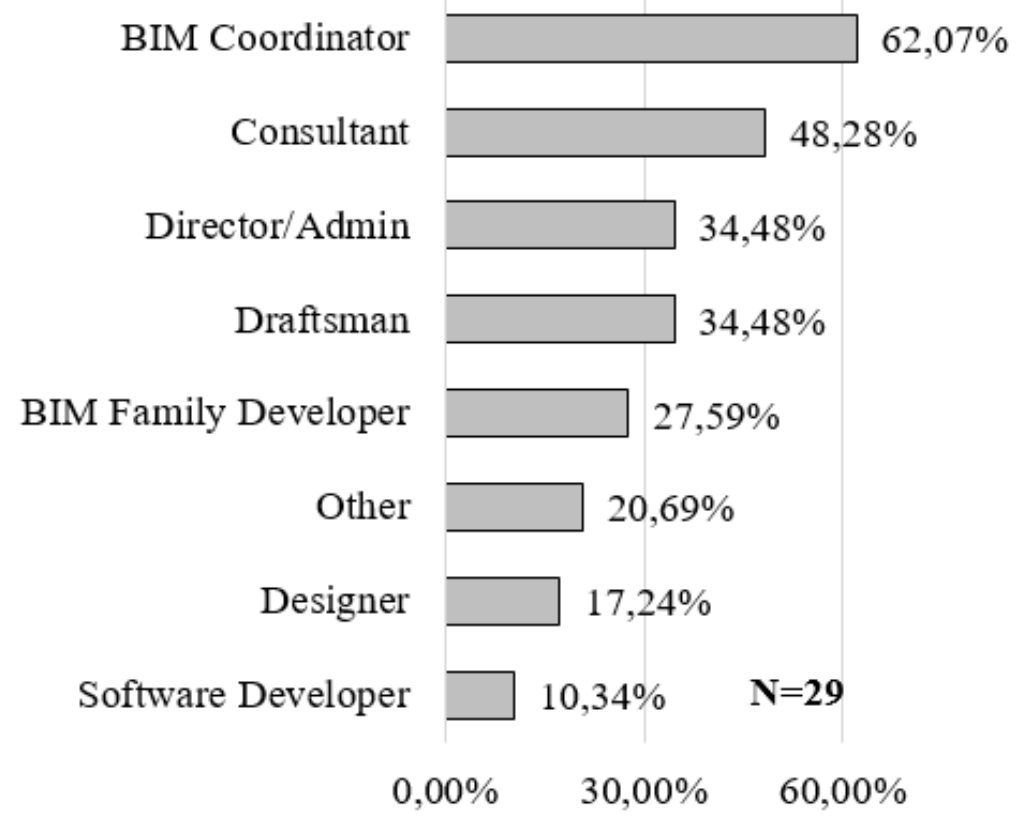

Fig. 3 Respondents' professional positions.

When questioned about which BIM software they use for architecture, with the option of selecting more than one alternative, the main responses were: Autodesk Revit (93.1\%) and GraphisoftArchicad (17.2\%).

To elucidate adoption of BIM technology in design processes and to further characterize the professional profile of the respondents, they were questioned about: the greatest difficulty found in BIM implementation; how communication between team members is made and; how sharing and transferring of BIM models between professionals is given, answers were gathered following methodology criteria for narrative responses.

Among the obstacles to BIM implementation by the respondents are the following: adaptation to the new integrated and collaborative way of designing, software costs and complexity, migration of old and familiar tools to BIM, time necessary for team training, low integration between management software and modeling software, lack of technology knowledge by partner designers, suppliers and even clients, market adaptation, interoperability between BIM software still developing and adequacy of components to Brazilian standards.
According to the respondents, communication between designers is given in a variety of ways, from more personal forms such as verbal communication at workstations and meetings, to emails, internal work sets, intranets and collaborative systems.

Respondents answered that the transfer of information model files between designers during project stages is done through means such as extranets, cloud computing, internal repositories and file exchange networks, some respondents also stated that file formats common to Autodesk platforms are integrated through Revit Link and Collaborate option, however, when receiving files from other platforms, some professionals declared to use IFC (industry foundation classes) format to enable interoperability.

To further elucidate the use of the open BIM format by the respondents, when presented to the following statement: "Current IFC satisfies interoperability needs between platforms", it was possible to observe balanced positions between agreement (13 responses) and discordance (8 responses), from a total of 25 respondents, a mean score of 3.24 in the Likert scale, relatable to the different ways the professionals use the open format functionalities. 


\subsection{Professional Plug-in Uses and Necessity}

Among the respondents, 58.6\% declared using plug-ins or extensions related to BIM authoring tools in their design processes. The professionals then were presented to some statements, and by Likert scale responses, could express their opinion in values from 1 (totally disagrees) to 5 (totally agrees) in relation to plug-in, extension and programming use for diverse purposes. Table 3 shows mean and standard deviation values from the statements' responses.

Based on this question, it is possible to affirm that there is agreement between the professionals, which demonstrates that the respondents believe in the potential of programming as a way to increment their design processes. This conclusion becomes clearer when professionals answer the following: "How can programming help in improving design processes?". Following narrative question methodology, among the main responses are: (1) productivity improvements: enabling automation of repetitive tasks, checking and validation of standards and methods, performing manual tasks such as family editing with agility, reducing operational tasks; (2) accuracy improvements:

Table 3 Plug-in and programming statement agreement.

\begin{tabular}{|l|l|l|l|}
\hline \multicolumn{1}{|c|}{ Statement } & N & Mean & $\begin{array}{l}\text { Std. } \\
\text { Dev. }\end{array}$ \\
\hline $\begin{array}{l}\text { 1- The use of plug-ins and/or } \\
\text { extensions can improve } \\
\text { productivity. }\end{array}$ & 25 & 4.60 & 1.31 \\
\hline $\begin{array}{l}\text { 2- The use of plug-ins and/or } \\
\text { extensions optimizes } \\
\text { decision making steps. }\end{array}$ & 24 & 4.42 & 1.07 \\
\hline $\begin{array}{l}\text { 3- The use of plug-ins and/or } \\
\text { extensions simplifies } \\
\text { repetitive design processes. }\end{array}$ & 25 & 4.60 & 1.24 \\
\hline $\begin{array}{l}\text { 4- Project area professionals } \\
\text { can use programming to } \\
\text { reach new levels of } \\
\text { excellence in designing } \\
\text { their projects. }\end{array}$ & 27 & 4.59 & 1.34 \\
\hline $\begin{array}{l}\text { 5- Project area professionals } \\
\text { can use programming to } \\
\text { reach new levels of } \\
\text { excellence in performance } \\
\text { of their projects. }\end{array}$ & & 4.61 & 1.36 \\
\hline
\end{tabular}

reducing the margin of error in complex modeling processes, identifying conflicts and consequently minimizing rework; (3) design improvements: increased productivity provides more dedicated time for solution development and compatibilization, enabling the design of more complex forms with more details and annotations, as well as generative design; (4) interoperability improvements: facilitating interchange between BIM applications, freeing models of some restrictions between platforms; (5) management improvements: facilitating coordination and communication among team members, offering solutions directed to specific company flows, reducing wastes from mistakes and making it possible to increase company profits.

When questioned whether they develop plug-ins, 5 professionals (17.2\%) declared that yes, among which the developed plug-ins' functionalities raised were: numbering and creation of structural elements, topographical surface finishing, automatic creation of wall coating, synchronization of schedules with budget and cost composition data lists, design and documentation of partition walls, information management at the construction site, creation of parametric components and communication management among company professionals.

When asked to quote through text field, names of plug-ins they use in their design processes, a total of 43 plug-ins names were raised, of these, 27 were already included in the quantitative research of plug-in repositories, the 16 remaining were searched for their functionalities and then used to increment the database of secondary repositories, feedbacking the state of the art.

Through plug-in detection device, it became possible to research the use of plug-ins by the professionals, following the same categorization methodology, enabling assessment of main purposes of the tools used (Fig. 4).

In Fig. 7, it is possible to notice the predominance of component based plug-ins $(44.19 \%)$, which reflects a 
possible relation with the current state of BIM technology implementation of the respondents, most of which are graduated in architecture, who can use plug-ins of this nature for purposes of modeling families, designing and rendering buildings and interiors.

The predominantly cited conversion plug-ins (20.93\%) are related to increased cross-platform collaboration and information maintenance, enabling additional ways to integrate information modeling between different software, sometimes to complement the interoperability of IFC format, which, as presented previously, has different levels of agreement in relation to its utility in design process by the respondents.

Productivity plug-ins, albeit being the most frequently developed in repository communities (36.17\% of state of art), were among the least utilized, with only $6.98 \%$ of use by the respondents. Such result makes it possible to infer that the plug-ins available in this category sometimes do not meet the specific needs of the professionals.

Performance plug-in category, although also seldom used by the professionals $(6.98 \%)$ is available in much smaller quantities in repositories $(3.38 \%$ of state of the art), their uses by the respondents are related to sustainable building design, energy efficiency, accessibility and landscapes.

In MEP and structural categories, similar percentages show approximation of use by professionals $(9.30 \%$ and $11.63 \%$, respectively) and available in repositories $(6.88 \%$ and $11.14 \%$, respectively).

Next, analysis of respondents' plug-in needs was made, this time, the professionals could suggest by text field, a plug-in which they would like to be developed or that would be useful in their design processes. The suggestion text was then interpreted through the described data and then, a matching category was proposed, based on the context of responses and following methodology. A total of 26 possible plug-ins have been described, with this information, it was possible to compare the suggested plug-ins with state of art categories (Fig. 5).

The results of this interaction with the professionals reveal that, although important to manipulate different file formats and to facilitate information interoperability, conversion plug-ins were not described in the suggestions. Instead, the respondents highlighted the necessity for applications in component (23.08\%), MEP and structural (both at 19.23\%) areas, presenting suggestions such as plug-ins for parametric furniture design, modular containers and generative design routines, as well as plug-ins that facilitate calculation related to electric projects, roof framing, reinforced concrete rebar and structural standard appropriate design.

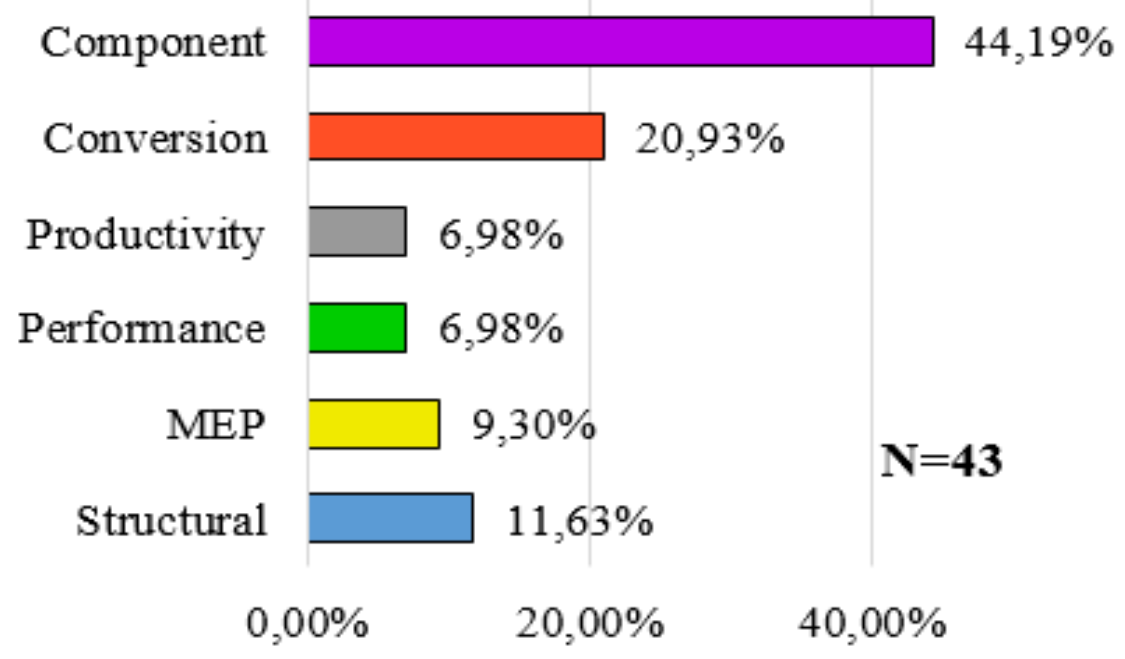

Fig. 4 Revit plug-ins-by use. 


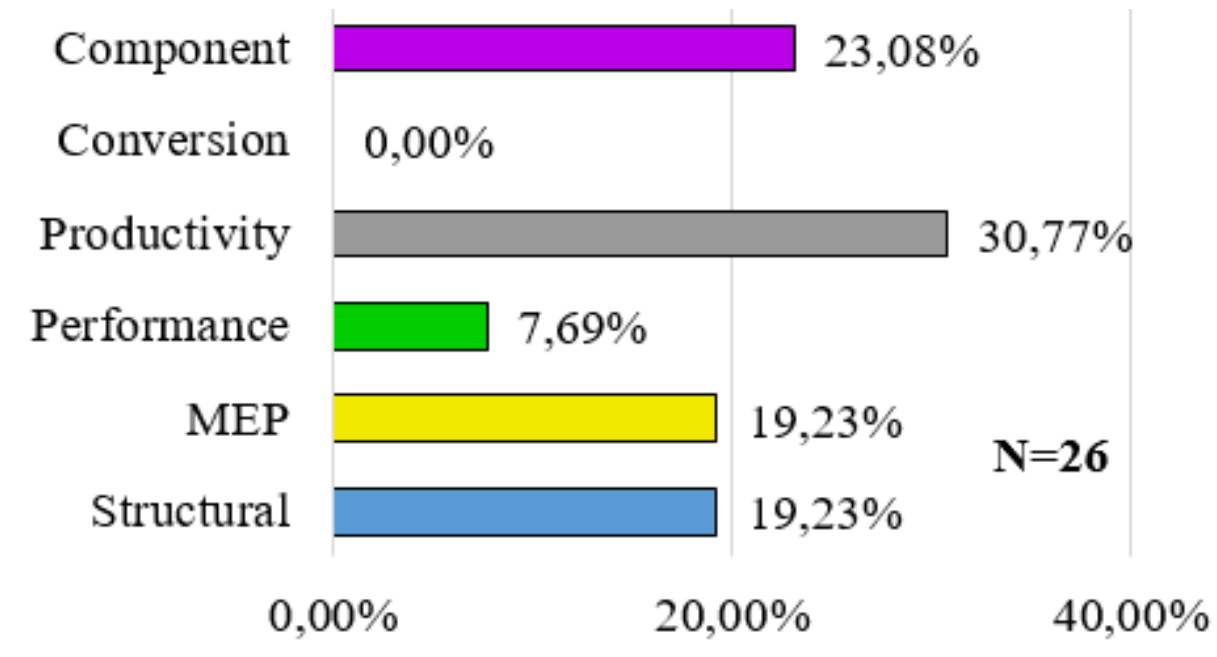

Fig. 5 Revit Plug-ins-suggested.

The interest for new productivity plug-ins (30.77\%) when related with previous results of this category, indicates that plug-ins used by professionals (6.98\% of use) possibly do not meet specific productivity demands of respondents, this information is further understood when a large number of plug-ins in this category are available in repositories $(36.17 \%$ of state of the art).

Performance plug-ins described (7.69\%) were connected mostly to design focused on accessibility, not directly referring to life cycle analysis, sustainable design, energy efficiency or environmental impacts, such occurrence serves as motivation for the next stage of this paper.

\subsection{Performance Plug-ins Analysis}

Seeking to elucidate the reason for this category to have so few developments in the state of the art, but having an average use and necessity by the respondents when compared to its availability, an analysis of possible performance plug-ins was carried out, starting from a five point Likert scale of agreement, according to methodology, addressing several topics related to the performance category. This approach was carried out under two perspectives: NBR 15.575 and environmental certifications.

4.4.1 NBR 15.575-Brazilian Performance Standard Complying with the current context of BIM in Brazil, with the increasing constructive systems' quality requirements, introduced by the Brazilian performance standard, the respondents could express their agreement regarding possibility of integrating current BIM technology with the following aspects of NBR 15.575 (Table 4).

Structural, thermal and light performance, as well as accessibility and functionality were the aspects that reached the highest mean agreement, possibly due to the presence of specific software tailored for these purposes already in the market, which perform analysis through simulations and rule checking in these contexts.

While part of the aspects were marked by impartiality, in the mean result, none of them pointed to

Table 4 BIM vs NBR 15.575 aspects agreement.

\begin{tabular}{|l|l|l|l|}
\hline NBR 15.575 aspect & No. & Mean & Std. Dev. \\
\hline Accessibility and functionality & 27 & 4.37 & 0.97 \\
\hline Structural performance & 28 & 4.36 & 1.00 \\
\hline Thermal performance & 28 & 4.25 & 0.90 \\
\hline Light performance & 28 & 4.25 & 0.90 \\
\hline Durability and maintainability & 26 & 4.08 & 0.92 \\
\hline Acoustic performance & 27 & 3.85 & 0.63 \\
\hline Fire safety & 27 & 3.81 & 0.72 \\
\hline Safety in use and operation & 24 & 3.79 & 0.68 \\
\hline Sealing and waterproofing & 26 & 3.65 & 0.61 \\
\hline $\begin{array}{l}\text { Tactile and anthropodynamic } \\
\text { comfort }\end{array}$ & 22 & 3.64 & 0.57 \\
\hline Health, hygiene and air quality & 23 & 3.61 & 0.53 \\
\hline Environmental suitability & 23 & 3.43 & 0.60 \\
\hline
\end{tabular}


partial or total disagreement, demonstrating that, according to the respondents, there is possibility of integrating BIM technology, at different levels, throughout the standard's aspects. This information is further supported when the respondents are presented to the following statement: "Current BIM possesses enough technology to meet requirements of performance standards in projects" (Fig. 6).

In Fig. 6, it is possible to note the distinction of partial agreement regarding the respondents positioning which indicates that such integration could be made, however with limitations. Seeking to elucidate what these difficulties would be, the professionals answered in a text field, the main obstacles in meeting NBR 15.575 requirements in design processes, following the methodology for narrative responses, the main answers were: (1) problems related to people involved: on one hand, lack of knowledge of performance standard's aspects by project professionals, on the other, shortage of qualified suppliers who specify performance data in product specifications; (2) problems related to information: lack of information related to performance standard in BIM families and components, difficulties in presenting, sharing and maintaining object data between design disciplines and the fact that analysis of many of the standard's requirements is done by constructive system rather than by separate elements, making it difficult to interconnect data to component joints.

Such information further characterizes the respondent's current design processes and makes it possible to direct new plug-in analysis. Professionals are then questioned as to the viability of BIM platform plug-ins to meet specificities of design practice aimed at performance, by integrating NBR 15.575 and BIM through plug-ins.

It is possible to notice a considerable increase in professional agreement when plug-ins are inserted in the context as a way to reach performance standard's requirements (Fig. 7), since the mean went from 3.75 to 4.21 in comparison, demonstrating that the focus on specificities provided by external applications can make it possible to improve performance-oriented design processes.

\subsubsection{Environmental Certifications}

The second part of performance category plug-in analysis was made by means of presentation of concepts

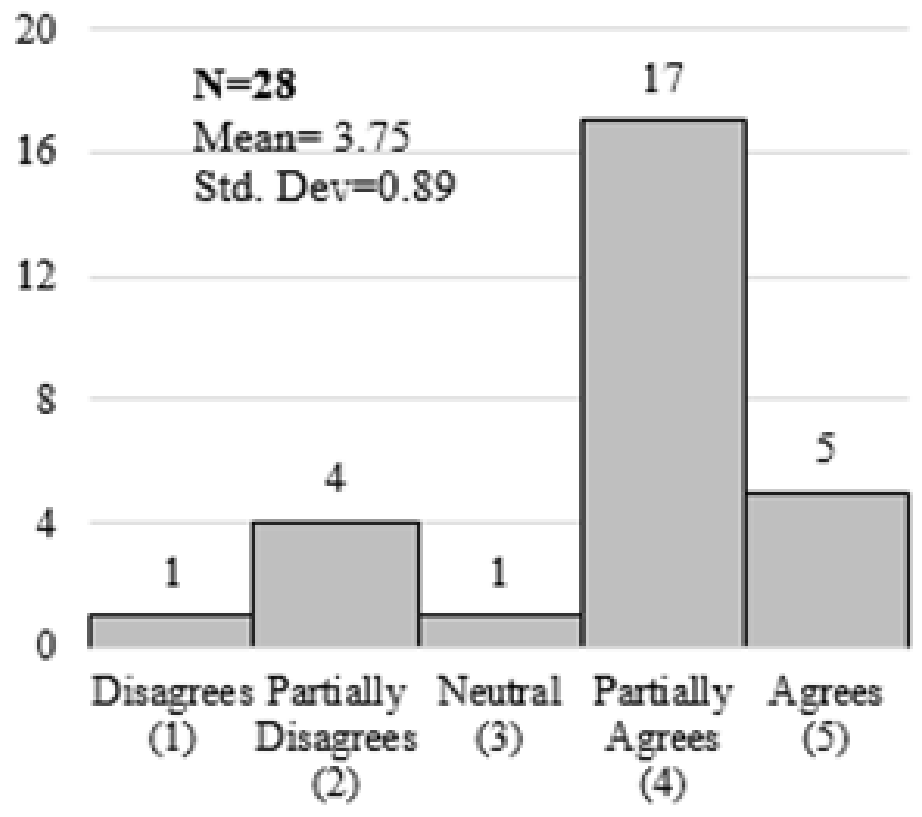

Fig. 6 BIM and NBR 15.575 integration statement agreement. 


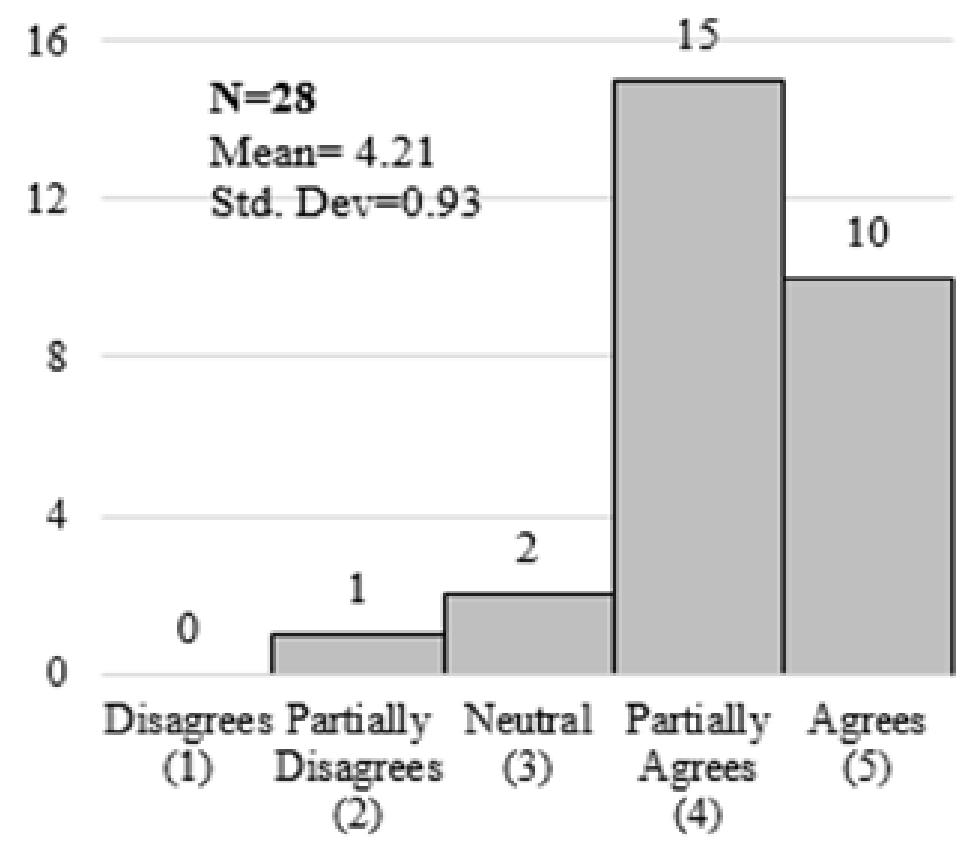

Fig. 7 Integration of NBR 15.575 through plug-ins agreement.

of environmental certification or green building seals to the professionals, areas of knowledge in which requirements for adoption are directly connected to diverse fields of sustainable building, enabling through its integration with BIM, to possibly provide development of Performance plug-ins.

From the respondents, $41.4 \%$ declared to have been involved in environmental certification adoption processes, from which, $91.7 \%$ declared to have participated in LEED certification, 50\% in Aqua and $8.3 \%$ in other certifications such as ISO 14.001, Casa Azul and ProcelEdifica.

From the intersection of common groups of requirements between the environmental certifications shown in the questionnaire, it was possible to ask the professionals about the possibility of current BIM technology integration in design processes focused on attaining aspects related to sustainable building requirements (Table 5), using the same methodology applied for Brazilian performance standard.

It was possible to verify greater agreement among the professionals on BIM integration with specific environmental certification aspects when compared to the results of the same approach on the performance standard. This is possibly associated to the current absorption of NBR 15.575 concepts by professionals, in relation to already more consolidated knowledge in sustainable construction project practice, as well as a possible familiarity of the respondents with the aspects presented in this situation. Such an increase in agreement can be further examined when the professionals are presented to the statement: "Current BIM can be used to attain environmental certification requirements" (Fig. 8).

As was done for performance standard, professionals were questioned through text field, to share

Table 5 BIM vs. environmental certification requirements agreement.

\begin{tabular}{|l|l|l|l|}
\hline Certification requirement & No. & Mean & Std. Dev. \\
\hline Illumination & 27 & 4.48 & 1.12 \\
\hline Thermal comfort & 25 & 4.44 & 1.21 \\
\hline Solar heating & 25 & 4.44 & 1.19 \\
\hline Ventilation & 26 & 4.38 & 1.01 \\
\hline Construction waste management & 24 & 4.17 & 0.86 \\
\hline Water reuse & 25 & 4.16 & 0.85 \\
\hline Sustainable materials & 25 & 4.12 & 0.86 \\
\hline Acoustic comfort & 25 & 4.04 & 0.76 \\
\hline Sustainable construction site & 25 & 4.00 & 0.73 \\
\hline Emission control & 23 & 3.87 & 0.67 \\
\hline
\end{tabular}




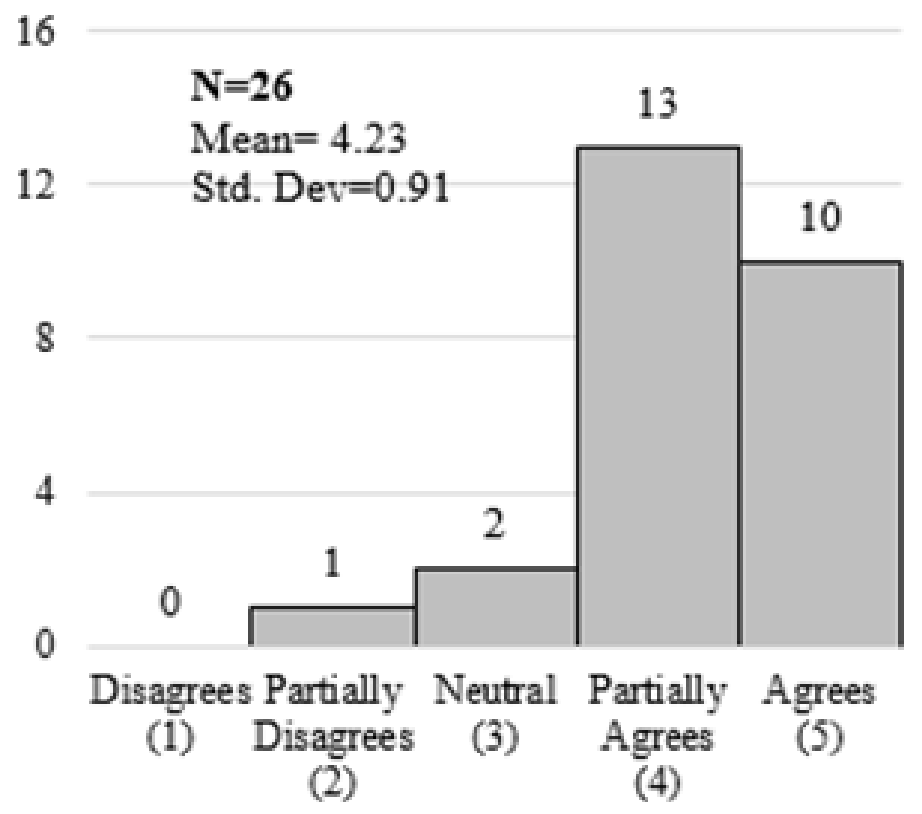

Fig. 8 BIM and environmental certification agreement.

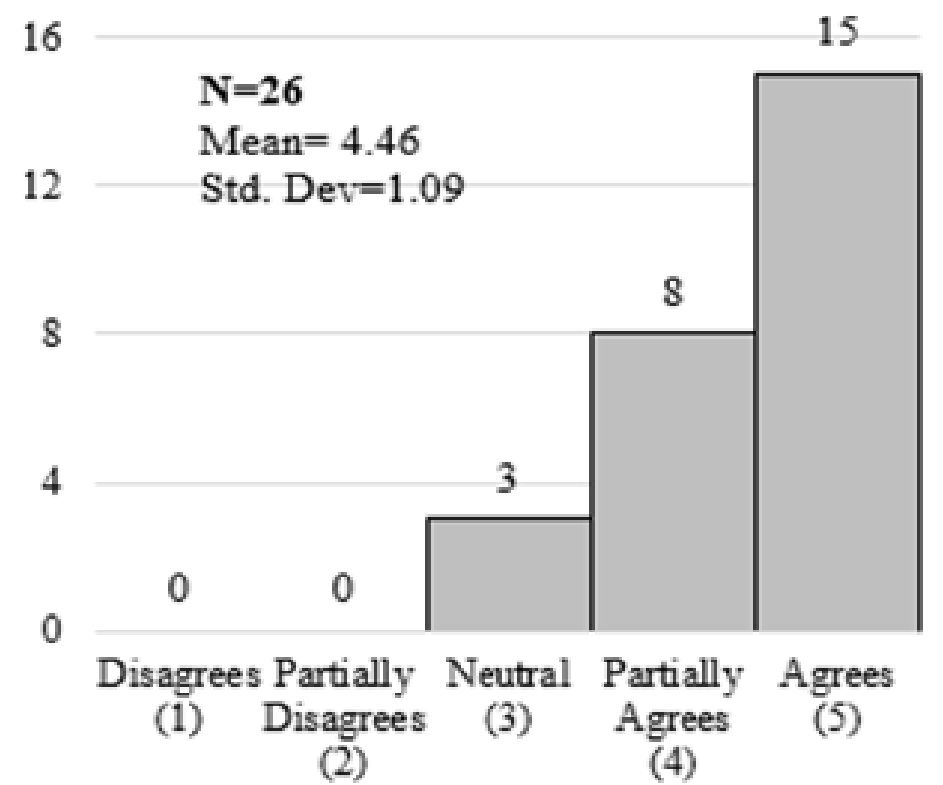

Fig. 9 Integration of environmental certification through plug-ins agreement.

the main difficulties in meeting environmental certification requirements in design processes of sustainable buildings. Following the methodology for narrative responses, the highlighted answers are: (1) problems related to software: lack of tools to support certification processes, necessity of inclusion of basic libraries with focus on sustainable materials in architecture software and scarcity of necessary parameters in construction models; (2) problems related to people: lack of experience of project team members in certification processes, needing to rely on specialized professionals; (3) problems related to information: difficulties to obtain and share referential data to assess necessary information for specific requirements, complications in cost monitoring related to decision making and energy efficiency technology 
changes.

These statements possibly subsidize the creation of performance based plug-ins in BIM platforms, with the purpose of attaining specific requirements of environmental certifications. Upon being questioned about this possibility, the professional answered positively, without disagreements (Fig. 9), reaching a mean agreement value of 4.46, even higher than that of NBR 15.575 interaction (mean 4.21).

\section{Final Remarks}

This work presented a quantitative research about plug-ins developed in repositories, proposing a classification of external applications in six distinct categories and assessing the state of the art, then this categorization was introduced in a real context through a questionnaire to AEC professionals, Brazilians, users of BIM technology and relatively experienced in design processes. It was then possible to evaluate the proposed state of the art of Autodesk Revit platform plug-ins, by means of interrogation about use and necessity of these tools in the respondents' context.

The contribution is in the study of BIM in conjunction with plug-ins in AEC companies, and can subsidize future work related to BIM platform external applications such as plug-ins, helping in the development of this technological field of BIM and seeking to point out solutions for project optimization through the use of programming.

As an additional contribution, an analysis and survey of plug-ins possibly related to building performance was made through the study of the professional's main difficulties, showing that, although the performance category is the least produced by repositories' communities, it has the potential to meet design practices in different ways, such as in the compliance of constructive systems with performance standard's requirements, as in the insertion of sustainability concepts in project processes in order to obtain environmental certifications.

\section{Acknowledgments}

The authors of this paper would like to thank Postgraduate Program in Architecture and Urbanism (PPGARQ) of the Polytechnic School at Faculdade Meridional (IMED), Programa de Suporte à Pós-Graduação de Instituições de EnsinoParticulares (PROSUP) and CAPES (Coordenação de Aperfeiçoamento de Pessoal de Nível Superior), for the financial assistance through scholarships that enabled this research.

\section{References}

[1] Eastman, C., Liston, K., Sacks, R., and Teicholz, P. 2008. BIM Handbook: A Guide to Building Information Modeling for Owners, Managers, Designers, Engineers and Contractors. Hoboken: John Wiley \& Sons.

[2] Succar, B., Sher, W., and Williams, A. 2012. "Measuring BIM Performance: Five metrics." Architectural Engineering and Design Management 8 (2): 120-42.

[3] Garbini, M. A. L., and Brandão, D. Q. 2014. "Proposta de Modelo para Implantação de Processo de Projeto Utilizando o Conceito BIM em Escritórios de Arquitetura." Gestão e Tecnologia de Projetos 9 (1): 7-24. (in Portuguese)

[4] Associação Brasileira De Normas Técnicas. 2013. NBR 15575-1: Edificações Habitacionais-Desempenho. Parte 1: Requisitos Gerais. Rio de Janeiro. (in Portuguese)

[5] Jalaei, F., and Jrade, A. 2014. "An Automated BIM Model to Conceptually Design, Analyze, Simulate, and Assess Sustainable Building Projects.” Journal of Construction Engineering 1-21.

[6] Autodesk. 2016. Revit API Developers Guide. Accessed November 10, 2016. https://knowledge.autodesk.com/ support/revit-products/learn-explore/caas/CloudHelp/clou dhelp/2014/ENU/Revit/files/GUID-F0A122E0-E556-4D 0D-9D0F-7E72A9315A42-htm.html.

[7] Matcha, H., and Quasten, G. 2009. “'A Parametric-Typological Tool': More Diversity for Mas Produced Single Family Homes through Parametrized Design and Customized Mass Production, in Design Tool Development." Presented at the 27th eCAADe Conference, Istanbul, Turkey, 409-416.

[8] Brígitte, G. T. N., and Ruschel, R. C. 2016. "Modelo de Informação da Construção para o Projeto Baseado em Desempenho: Caracterização e Processo." Ambiente Construído 16 (4): 9-26. (in Portuguese)

[9] Ruschel, R. C., Valente, C. A. V., Cacere, E., and Queiroz, S. R. S. L. 2013. "O Papel das Ferramentas BIM de Integração e Compartilhamento no Processo de Projeto na 
Indústria da Construção Civil.” REEC-Revista Eletrônica de Engenharia Civil 7 (3): 36-54. (in Portuguese)

[10] Li, J. 2016. “Integrating Building Information Modelling (BIM), Cost Estimating and Scheduling for Buildings Construction at the Conceptual Design Stage.” Master's degree thesis, Faculty of Engineering, Ottawa-Carleton Institute for Civil Engineering, University of Ottawa, Canada.

[11] Schlueter, A., and Thesseling, F. 2009. "Building Information Model Based Energy/Exergy Performance Assessment in Early Design Stages.” Automation in Construction 18 (2): 153-63.

[12] Wu, W. 2010. "Integrating Building Information Modeling and Green Building Certification: The BIM-Leed Application Model Development. ” Ph.D. dissertation, Design, Construction and Planning, University of Florida, Florida.

[13] Sanhudo, L. P. N. 2016. "BIM for Building Sustainability Assessment: Development of a Software Tool for Rainwater Runoff mitigation.” Master's degree dissertation, Curso de Engenharia Civil, Faculdade de Engenharia da Universidade do Porto, Porto, Portugal.

[14] Stadel, A., Eboli, J., Ryberg, A., Mitchell, J., and Spatari, S. 2011. "Intelligent Sustainable Design: Integration of Carbon Accounting and Building Information Modeling.” Journal of Professional Issues in Engineering Education and Practice 137 (2): 51-4.

[15] Zhang, C., Chen, S., and Kang, B. 2015. "LEED
Embedded BIM for Construction Sustainability Analysis.” International Journal of Science Research and Technology 1 (1): 95-101.

[16] Revit Store. n.d. Plugins, Add-ons and Extensions for Revit. Accessed November 10, 2016. https://apps.autodesk.com/RVT/en/Home/Index.

[17] Tools4Revit. n.d. Homepage. Accessed November 10, 2016. http://tools4revit.cadtrainingonline.com/.

[18] AGACAD. n.d. Accessed November 10, 2016. http://www.aga-cad.com/products/tools4revit.

[19] AEC-APPS. n.d. Accessed November 10, 2016. https://aec-apps.com/plugins/for/Revit?page=0\%2C0.

[20] Case Apps. n.d. Github. Accessed November 10, 2016. https://github.com/WeConnect/case-apps.

[21] Kiwicodes. n.d. Accessed November 10, 2016. http://www.kiwicodes.com/11-products.

[22] BIM Interoperability Tools. n.d. Accessed November 10, 2016. http://www.biminteroperabilitytools.com/index.ht $\mathrm{ml}$.

[23] Revitworks. n.d. Accessed November 10, 2016. http://www.revitworks.co.nz/Products.aspx.

[24] David Pinto Consultoria. n.d. Accessed November 10, 2016. http://www.davidpintoconsultoria.com.br/.

[25] CGS Plus. n.d. Accessed November 10, 2016. http://usa.cgsplus.com/Products/CGSRevitTools.aspx.

[26] Ideate Software. n.d. Accessed November 10, 2016. http://ideatesoftware.com/.

[27] RTVTools. n.d. Accessed November 10, 2016. https://www.rtvtools.com/rtv-tools-plugins/. 